BMJ

Open

Gastroenterology

\section{Ustekinumab is effective for perianal fistulising Crohn's disease: a real-world experience and systematic review with meta-analysis}

To cite: Godoy Brewer GM, Salem G, Afzal MA, et al. Ustekinumab is effective for perianal fistulising Crohn's disease: a realworld experience and systematic review with metaanalysis. BMJ Open Gastro 2021;8:e000702. doi:10.1136/ bmjgast-2021-000702

- Additional supplemental material is published online only. To view, please visit the journal online (http://dx.doi. org/10.1136/bmjgast-2021000702).

Received 12 May 2021 Accepted 4 November 2021

Check for updates

(C) Author(s) (or their employer(s)) 2021. Re-use permitted under CC BY-NC. No commercial re-use. See rights and permissions. Published by BMJ.

For numbered affiliations see end of article.

Correspondence to Dr Alyssa M. Parian; aparian1@jhmi.edu

\section{ABSTRACT}

Background Perianal Crohn's disease (pCD) is a debilitating complication affecting up to $30 \%$ of Crohn's disease (CD) population, leading to increased morbidity, mortality and decreased quality of life. Despite the growing armamentarium of medications for luminal CD, their efficacy in PCD remains poorly studied.

Aim To determine the efficacy of ustekinumab, a biologic approved for luminal CD, in pCD through a retrospective cohort study and systematic review.

Methods A retrospective cohort study on patients with $C D$ with active perianal fistulae treated with ustekinumab from September 2013 to August 2019 was performed to determine perianal fistula response and remission at 6 and 12 months after ustekinumab induction. A systematic review was performed to further establish rates of fistula response and remission with ustekinumab.

Results At 6 months, 48.1\% (13/27) patients achieved fistula response with none achieving fistula remission on provider exam, and $59.3 \%$ (16/27) achieved patient-reported symptomatic improvement with 3.7\% $(1 / 27)$ achieving symptomatic remission. At 1 year, on provider exam, $55.6 \%(5 / 9)$ had fistula response with none achieving fistula remission, and 100\% (9/9) had symptomatic improvement with $22.2 \%$ (2/9) achieving symptomatic remission. There were no major safety signals during 1-year follow-up. The systematic review of 25 studies found $44 \%$ (92/209) of patients with active perianal fistulas had a clinical response within 6 months of follow-up, and $53.9 \%$ (85/152) of patients with 12 months of follow-up achieved clinical response.

Conclusion Ustekinumab presents a safe and effective therapy for treatment of $\mathrm{pCD}$. Prospective, randomised trials are needed to further elucidate long-term efficacy of ustekinumab for $\mathrm{pCD}$.

\section{INTRODUCTION}

Perianal fistulae are debilitating complications that affect up to $30 \%$ of the Crohn's disease (CD) population and can be associated with severe symptoms. ${ }^{12}$ Perianal Crohn's disease (pCD) has a disabling course leading to increased morbidity, mortality and a significantly decreased quality of life. ${ }^{3}$ The treatment for perianal fistulae is complex. Despite the growing armamentarium of medications for the treatment of luminal CD, the efficacy of these therapies in pCD remains poorly reported. Infliximab is currently the only therapy with prospective data on perianal fistula response and remission. However, at 1 year, only $36 \%$ of patients achieved sustained remission of their pCD. ${ }^{5}$

There are other therapies used for pCD, but the data are limited to retrospective studies and post hoc analyses of clinical trials for luminal CD. No medication has been shown to be more than $40 \%$ effective in maintaining sustained remission in pCD, creating an urgent need for further studies evaluating new mechanisms of action.

Ustekinumab has a novel mechanism of action which inhibits interleukin-12 and interleukin-23 in the inflammatory pathway and was approved for the treatment of moderate to severe CD in $2016 .{ }^{56}$ The published trials show a statistically significant difference over placebo in induction and maintenance of remission for luminal $\mathrm{CD}$ with an excellent safety profile; however, ustekinumab's efficacy in perianal fistula healing is still lacking. ${ }^{7}$

The aim of the current study was to determine the efficacy of ustekinumab in the treatment of pCD through a retrospective cohort study combined with a systematic review and meta-analysis.

\section{METHODS}

\section{Retrospective cohort study}

Selection of patients

A retrospective cohort study was performed at a large single tertiary referral centre. The 
inflammatory bowel disease (IBD) registry was searched for adult ( $\geq 18$ years) patients with active $\mathrm{pCD}$ who received treatment with ustekinumab for luminal and/ or perianal CD from September 2013 to August 2019. Patients were included if they (1) had a confirmed diagnosis of active pCD through provider exam, (2) received at least one dose of intravenous or subcutaneous ustekinumab, and (3) had follow-up exam after the initial dose of ustekinumab. Patients were excluded if they (1) had a diagnosis of ulcerative colitis, (2) had rectovaginal fistula without perianal fistulae, (3) had an active malignancy aside from basal cell or squamous cell skin cancers, or (4) were using ustekinumab for reasons other than CD. Entry into the study was the date of ustekinumab induction. Patients were censored at the time of their last follow-up, up to 12 months after ustekinumab initiation.

\section{Data collection}

Patient demographics, disease characteristics, and prior/ concurrent CD medications were recorded. Serum C reactive protein (CRP) levels were noted within 3 months prior to induction with ustekinumab, and at intervals of $6( \pm 1$ month $)$ and $12( \pm 1$ month $)$ months after induction. Due to varying CRP assays and normal values, CRP data were reported as improvement from baseline (at least $10 \%$ improvement in CRP value), normalisation (CRP decreased from elevated baseline into the normal range) or no improvement. Data regarding patientreported symptoms and provider physical examination were extracted from the standardised template of IBD visits. Colonoscopy reports and images were reviewed within 3 months prior to induction and at intervals of 6 and 12 months after induction to note rectal endoscopic response.

\section{Primary and secondary outcomes}

The primary outcomes were provider-based perianal fistula response and remission and patient-reported symptomatic response and remission at 6 and 12 months after ustekinumab induction. Provider-based perianal fistula response was defined as at least $50 \%$ decrease in fistula drainage compared with baseline as assessed by the provider's physical examination 'without need for surgical intervention'. Provider-based perianal fistula remission was defined as closure of the external fistula opening and complete cessation of drainage with compression of the tract. Patient-reported symptomatic response was defined as patient-reported improvement in fistula pain and/or decreased drainage. Patient-reported symptomatic remission was defined as patient-reported absence of perianal pain and complete cessation of fistula drainage. Patients who developed perianal complications, such as abscesses, were considered non-responders.

Secondary outcomes were (1) improvement in serum (CRP); (2) rectal endoscopic response, defined as absence of rectal ulcers and reduction in inflammation compared with previous endoscopic studies, and endoscopic remission defined as evidence of normal rectal

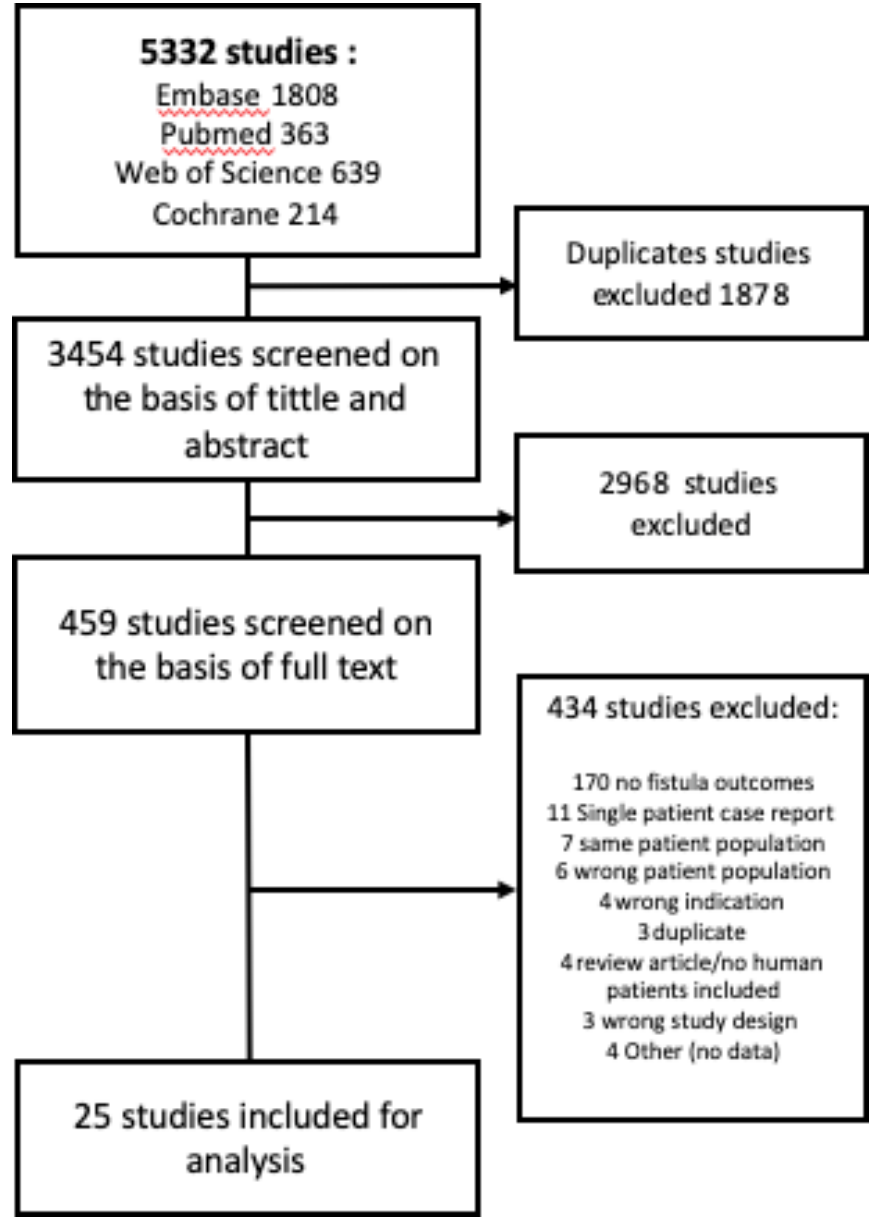

Figure 1 The Preferred Reporting Items for Systematic Reviews and Meta-Analyses flow diagram.

mucosa without ulcers, erosions or friability; (3) ability to wean off steroids; (4) requirement of ustekinumab dose escalation; (5) need for hospitalisation or surgical intervention related to perianal disease; and (6) rate of infections or other adverse events due to ustekinumab therapy.

\section{SYSTEMATIC REVIEW WITH META-ANALYSIS Meta-analysis information sources}

A systematic review with meta-analysis was performed to evaluate the efficacy of ustekinumab for subjects with pCD. Using Preferred Reporting Items for Systematic Reviews and Meta-Analyses guidelines, candidate studies for inclusion into this review were identified through systematic literature searches in MEDLINE (PubMed), Embase (Embase.com), the Cochrane Library (Cochrane Database of Systematic Reviews, Cochrane Central Register of Controlled Trials, and Cochrane Methodology Register), and Web of Science (figure 1). The search strategy was developed and executed by a library informaticist in collaboration with the clinical team. All searches were performed in July 2021. Keywords were used to develop the search strategies for all databases as well as appropriate controlled vocabulary terms in MEDLINE, Embase, and Cochrane. The bibliographies 
and reference lists of key citations related to the topic were also hand-searched for additional relevant citations.

\section{Eligibility criteria}

Studies were included in the systematic review if they met the following criteria: (1) paediatric or adult human studies that provided data on efficacy of ustekinumab for $\mathrm{pCD}$, and (2) prospective or retrospective studies which contained two or more patients with active perianal fistula. Exclusion criteria were (1) use of ustekinumab for diseases other than $\mathrm{CD}$, (2) review articles, (3) singlepatient case reports, and (4) non-human studies. For studies reporting the overall efficacy of ustekinumab without clear data on PCD, the authors were individually contacted to provide information related to perianal fistula outcomes. Patients were included if they had follow-up at the designated time points within the study.

\section{Study selection}

All titles and abstracts of retrieved articles were reviewed by two independent investigators. Full-length publications of selected articles were screened for final inclusion by two independent investigators. A third investigator served to adjudicate any discrepancies at all stages of study selection.

\section{Data collection}

From each included publication, the investigators retrieved the following information: (1) methodology; (2) publication year; (3) country where the study was performed; (4) setting (single centre/multicenter); (5) years when the study was conducted; (6) number of patients with CD with active perianal fistula; (7) number of patients with active perianal fistula treated with ustekinumab; (8) comparator agent (eg, placebo); (9) number of patients with pCD with response to ustekinumab and comparator therapy; (10) study definition of response; (11) time point(s) response was assessed; (12) number of patients with pCD that achieved remission with ustekinumab and comparator therapy; (13) study definition of remission; and (14) time point(s) remission was assessed.

\section{Risk of bias in individual studies}

The Newcastle-Ottawa Scale (NOS) was used to record the information on the methodological quality of each retrospective included study and for quality assessment. Grading of Recommendations Assessment, Development, and Evaluation (GRADE) framework was used to assess the quality of evidence for the included randomised controlled trial (RCT) study. ${ }^{8}$ Each study was reviewed by two blinded independent reviewers.

\section{Outcomes}

The primary outcomes were perianal fistula response and remission in patients with $\mathrm{CD}$ treated with ustekinumab.

\section{Statistical analysis}

R Statistical Analysis V.3.6.1 was used for analyses. Patient and disease characteristics were presented with percentages (\%), means \pm SD and medians with IQR where appropriate.

\section{RESULTS}

\section{Retrospective cohort study}

Patient characteristics

Thirty-one patients with a diagnosis of $\mathrm{CD}$ and evidence of active perianal disease were treated with ustekinumab between May 2015 and August 2019. Patient demographics of the included patients are summarised in table 1 . The median age at ustekinumab induction was 36 years (IQR 27-43) and the median disease duration was 12.5 years (IQR 5.3-18.5). The majority of patients were female $(n=21,67.7 \%)$ and Caucasian $(n=19,61.3 \%)$. Colonic (L2) disease phenotype was most common (48.4\%), followed by ileocolonic (L3) (35.5\%) and ileal (L1) phenotype $(6.5 \%)$. More than half of the patients $(\mathrm{n}=19,61.3 \%)$ had a previous history of perianal surgery.

Twenty-three patients $(74.2 \%)$ had previously used immunomodulators. All but one patient $(n=30,96.8 \%)$ had prior anti-tumour necrosis factor (TNF) exposure: 8 (25.8\%) were exposed to one anti-TNF, $17(54.8 \%)$ were exposed to two anti-TNF and $5(16.1 \%)$ were exposed to three anti-TNF. Ten patients $(32.3 \%)$ had previous exposure to vedolizumab.

Thirty patients $(96.8 \%)$ were induced with intravenous weight-based doses of 260,390 or $520 \mathrm{mg}$ of ustekinumab, while 1 patient $(3.2 \%)$ was induced with a subcutaneous dose of $270 \mathrm{mg}$. Nine patients $(29 \%)$ were on steroids at the time of induction, six on prednisone and three on budesonide. Ten patients were using immunomodulators at the time of induction, 7 patients $(22.6 \%)$ on azathioprine, 1 patient $(3.2 \%)$ on 6 -mercaptopurine and 2 patients $(6.5 \%)$ on methotrexate.

\section{Primary outcomes}

Six-month follow-up was available for 27 patients with active perianal fistulising CD treated with ustekinumab. Provider-based perianal fistula response was seen in 13 patients $(48.1 \%)$, whereas provider-based perianal fistula remission was not seen in any patients at 6-month follow-up (figure 2A). Thirteen $(48.1 \%)$ patients demonstrated no change and 1 patient $(3.7 \%)$ had worsening perianal disease. Patient-reported symptomatic response was seen in 16 patients $(59.3 \%)$ with 1 patient $(3.7 \%)$ achieving patient-reported symptomatic remission. Eleven patients $(40.7 \%)$ had no symptomatic changes and no patients reported worsening perianal symptoms (figure 2B). Multivariable analysis of factors associated with fistula response to ustekinumab at 6 months with CIs is included in online supplemental table 1.

Twelve-month follow-up was obtained from nine patients. For provider-based outcomes, five patients $(55.6 \%)$ had perianal fistula response with no patients achieving remission. For patient-reported symptomatic outcomes, all patients $(\mathrm{n}=9,100 \%)$ had symptomatic 


\begin{tabular}{lc}
\hline Table 1 & Patient demographics and clinical characteristics \\
\hline Demographic variable & Frequency (\%) \\
\hline $\begin{array}{l}\text { Gender } \\
\text { Female }\end{array}$ & $21(67.7)$ \\
\hline Male & $10(32.3)$ \\
\hline Race & \\
Caucasian & $19(61.3)$ \\
African-American & $8(25.8)$ \\
Other & $4(12.9)$
\end{tabular}

Smoking status

\begin{tabular}{|c|c|}
\hline Never & $20(64.5)$ \\
\hline Former & $8(25.8)$ \\
\hline Current & $3(9.7)$ \\
\hline BMI (mean) (SD) & $25.5 \pm 5.7$ \\
\hline $\begin{array}{l}\text { Age at ustekinumab induction in years } \\
\text { (median) (IQR) }\end{array}$ & $36(27-43)$ \\
\hline $\begin{array}{l}\text { Duration of the disease at time of } \\
\text { induction in years (median) (IQR) }\end{array}$ & $12.5(5.3-18.5)$ \\
\hline \multicolumn{2}{|l|}{ Montreal classification-disease location } \\
\hline L1-ileal & $2(6.5)$ \\
\hline L2-colonic & $15(48.4)$ \\
\hline L3-ileocolonic & $11(35.5)$ \\
\hline L4-upper disease & $1(3.2)$ \\
\hline J pouch & $2(6.5)$ \\
\hline \multicolumn{2}{|l|}{$\begin{array}{l}\text { Montreal classification-behaviour of the } \\
\text { disease, } n(\%)\end{array}$} \\
\hline B1-non-stricturing, non-penetrating & $15(48.4)$ \\
\hline B2-stricturing & $3(9.7)$ \\
\hline B3-penetrating & $13(41.9)$ \\
\hline Previous history of perianal surgery & $19(61.3)$ \\
\hline Seton placement & $9(29)$ \\
\hline Fistulotomy & $4(12.9)$ \\
\hline Abscess drainage & $2(6.5)$ \\
\hline Fistulectomy & $2(6.5)$ \\
\hline Advancement flap & $1(3.2)$ \\
\hline Unknown & $1(3.2)$ \\
\hline Intestinal resection prior to induction & $13(41.9)$ \\
\hline $\begin{array}{l}\text { Current seton at time of ustekinumab } \\
\text { induction }\end{array}$ & $8(25.8)$ \\
\hline $\begin{array}{l}\text { Concurrent immunomodulators at } \\
\text { induction }\end{array}$ & $10(32.6)$ \\
\hline \multicolumn{2}{|l|}{ Previous use of immunomodulators } \\
\hline Azathioprine & $17(54.8)$ \\
\hline Methotrexate & $7(22.6)$ \\
\hline 6-mercaptopurine & $6(19.4)$ \\
\hline \multicolumn{2}{|l|}{ Prior biological exposure } \\
\hline Infliximab & $25(80.6)$ \\
\hline Adalimumab & $25(80.6)$ \\
\hline Vedolizumab & $10(32.3)$ \\
\hline Certolizumab pegol & $6(19.4)$ \\
\hline Golimumab & $1(3.2)$ \\
\hline
\end{tabular}
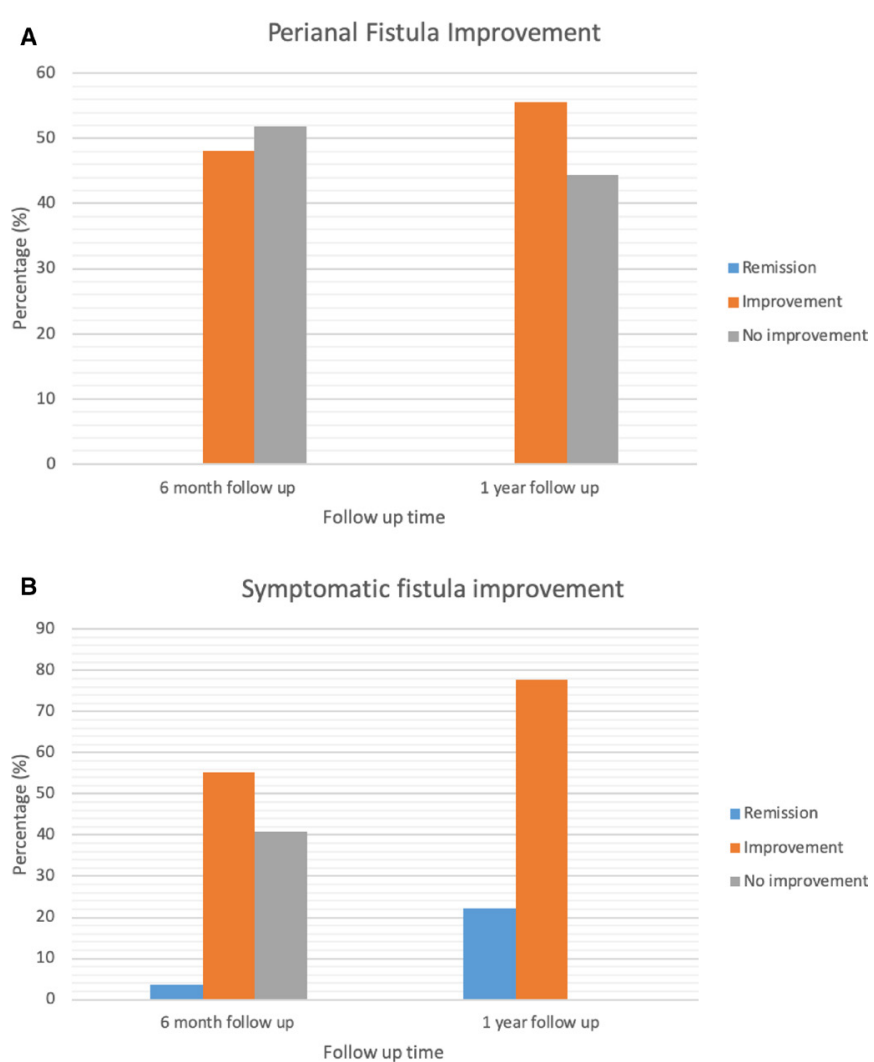

Figure 2 (A) Perianal fistula improvement according to provider clinical assessment. (B) Symptomatic fistula improvement according to patient global assessment.

response and two (22.2\%) achieved symptomatic remission.

\section{Secondary outcomes \\ CRP levels}

Preinduction and 6-month follow-up CRP levels were available from 13 patients at 6-month follow-up: $61.5 \%$ had normalised CRP levels; $23 \%$ had improvement without reaching normal levels. There was a $39 \%$ mean reduction of CRP levels which corresponded with improvement of patient-reported symptomatic response of perianal pain and drainage in $6 / 13(46.2 \%)$ patients.

CRP levels at 12 months were available from five patients: 3 (60\%) had normalised CRP levels, 1 (20\%) had improvement.

\section{Endoscopy}

Endoscopic surveillance prior to induction and at 6-month follow-up was available in nine patients. Six $(66.7 \%)$ patients had rectal endoscopic response, with two of these patients achieving endoscopic remission. Two $(22.2 \%)$ patients had no endoscopic change, and one patient $(11.1 \%)$ had worsening rectal disease.

Endoscopic surveillance at 1 year was obtained from three patients. Two patients maintained rectal endoscopic improvement and one patient had no change. 


\section{Dose escalation}

Eight patients $(29.6 \%)$ required dose escalation within 6 months of ustekinumab induction due to loss of response or incomplete response of luminal and/ or perianal disease. Two patients increased to every 6 weeks, and six patients were escalated to every 4 weeks. Four patients $(50 \%)$ experienced perianal symptomatic improvement after dose escalation, and two patients $(25 \%)$ did not experience any improvement. Follow-up data were not available in two patients to report their response to escalated dosing.

Two additional patients required dose escalation between 6 and 12 months on ustekinumab. One patient escalated to every 4 weeks but required a subsequent laparoscopic proctocolectomy with end ileostomy due to severe luminal disease and stopped ustekinumab. One patient escalated to every 6 weeks and had symptomatic improvement.

\section{Steroid use}

Of the 27 patients with 6-month follow-up, 5 (18.5\%) were using prednisone and $3(11.1 \%)$ were using budesonide at the time of induction. All five patients on prednisone and one patient on budesonide were able to taper off after initiation of ustekinumab. One patient required a new prednisone taper due to a flare of the luminal CD.

At 1-year follow-up, no further patients required new steroid therapy.

\section{Surgery}

Three patients $(11.1 \%)$ required surgeries within 6 months of ustekinumab induction. Two patients required perianal abscess drainage and seton placement. A third patient underwent a loop ileostomy for abdominal abscess and sepsis. At 1-year follow-up, four additional patients $(44.4 \%)$ required surgery with three related to perianal disease. Two patients had incision and drainage of perianal abscesses; one patient had a new seton placement; and one patient underwent a laparoscopic total proctocolectomy with end ileostomy due to severe luminal disease.

\section{Hospitalisation}

At 6-month follow-up, aside from hospitalisations from surgeries mentioned previously, three other patients required hospitalisations for flares of luminal CD.

Two additional patients required hospitalisations between 6 months and 1 year. One patient was hospitalised due to a haemolytic uraemic syndrome and the other patient was hospitalised for proctocolectomy with end ileostomy as mentioned earlier.

\section{Adverse events}

Six patients developed infections; two patients developed infusion/injection site reactions; and six patients developed other adverse events. The rate and type of adverse events are included in online supplemental table 2 .
Five patients $(18.5 \%)$ discontinued treatment within the first 6 months after induction. The reasons were hypereosinophilia, abdominal abscess requiring loop ileostomy, and lack of response in three patients. One additional patient $(11.1 \%)$ stopped ustekinumab between 6 and 12 months of follow-up due to surgery (complete proctocolectomy and end ileostomy).

\section{Patients with inactive perianal disease}

There were 25 patients that had inactive perianal disease at the time of ustekinumab induction and had a mean follow-up time of $86.2 \pm 49$ weeks. One of these patients developed a new perianal abscess requiring drainage 1 year after the induction of ustekinumab. None of the remaining patients developed a flare of the perianal disease during ustekinumab therapy.

\section{Meta-analysis}

Study selection

A total of 5332 studies were retrieved, of which 3078,677 , 1230 , and 347 studies were identified by the searches in Embase, PubMed, Web of Science, and Cochrane, respectively. After excluding the duplicates, 2564 were included, of which 463 underwent full-text screening and 25 publications were included in the analysis.

\section{Characteristics of the included studies}

The main characteristics of the included studies are provided in table 2 . Of the 25 included studies, $5(20 \%)$ were abstracts and $20(80 \%)$ were full manuscripts. Fourteen studies were multicentre $(56 \%)$. The majority $(n=21,84 \%)$ of studies were retrospective, three studies were prospective observational studies (12\%) and one (4\%) was a post hoc pooled analysis of several RCTs. Three studies $(12 \%)$ were performed with a paediatric population.

The study population was composed of 538 patients with a diagnosis of $\mathrm{CD}$ and active perianal fistula who underwent ustekinumab induction and 71 placebotreated patients. We included the 27 patients from our cohort study to the analysis for a total population of 565 ustekinumab-treated patients.

\section{Risk of bias assessment}

All studies used a medical record to access patient data and clinician expertise to evaluate the outcomes. Regarding assessment of outcomes, all studies reported the number of patients with active perianal disease and fistula, ustekinumab induction and perianal outcomes. NOS was used to record the information on the methodological quality for retrospective observational studies and for quality assessment (online supplemental table 3). Each study was reviewed by two blinded independent reviewers. For the RCT, we used the GRADE of evidence system; the study was reviewed (online supplemental table 4), graded and compared by two blinded independent reviewers.

The studies included demonstrated variability in the definition of perianal response and time frames selected for assessment of response/remission. 


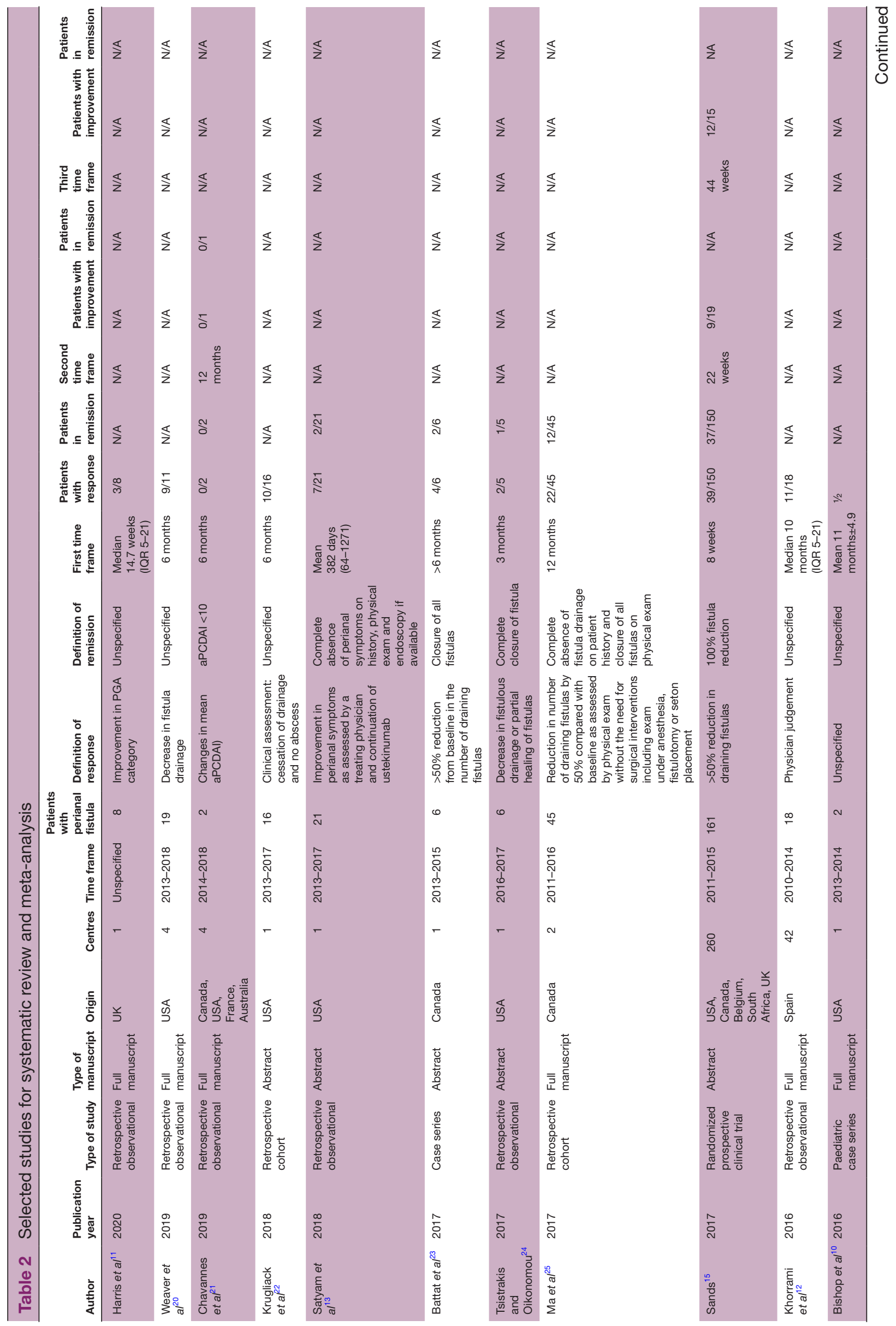




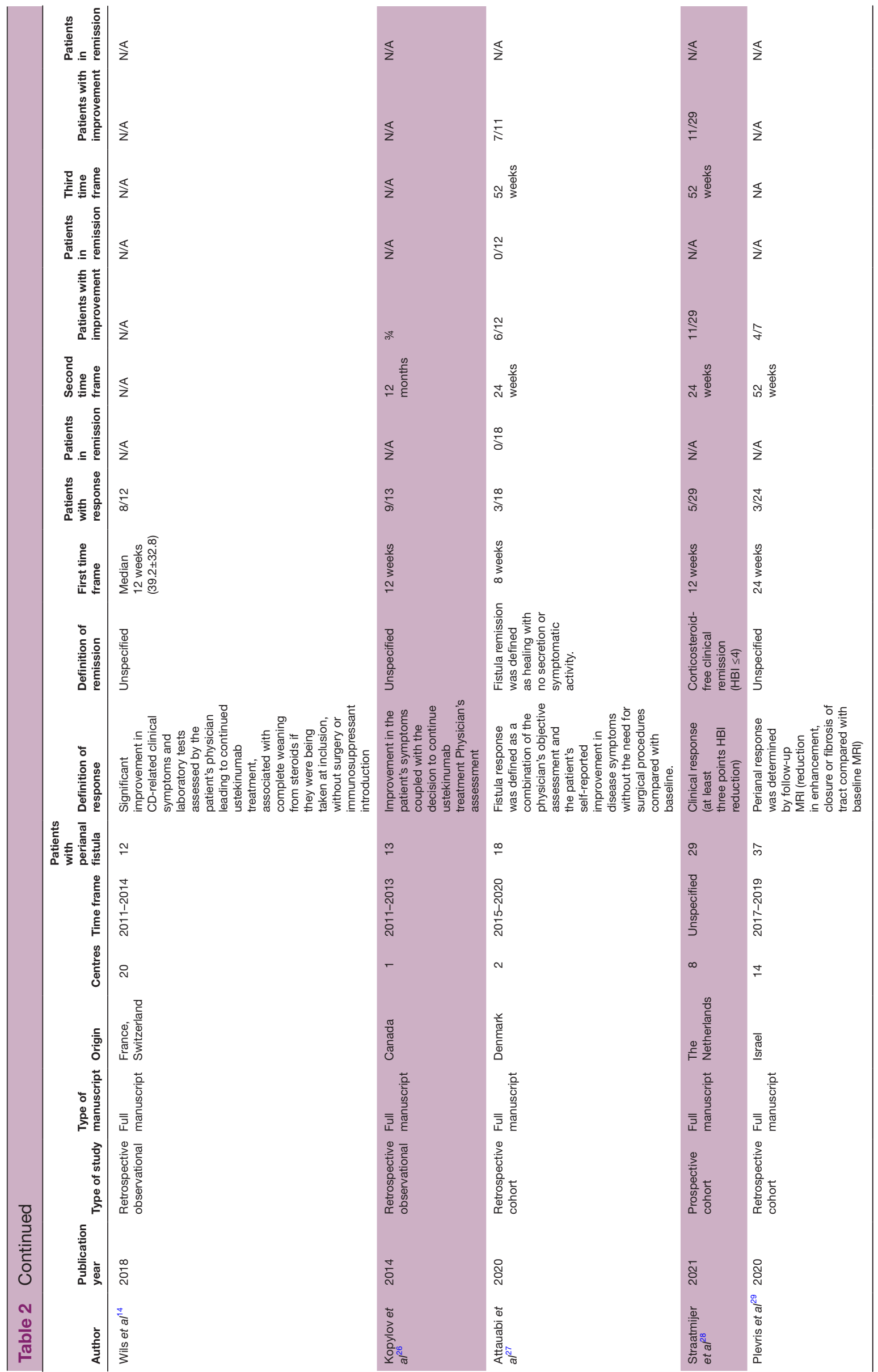




\section{Open access}

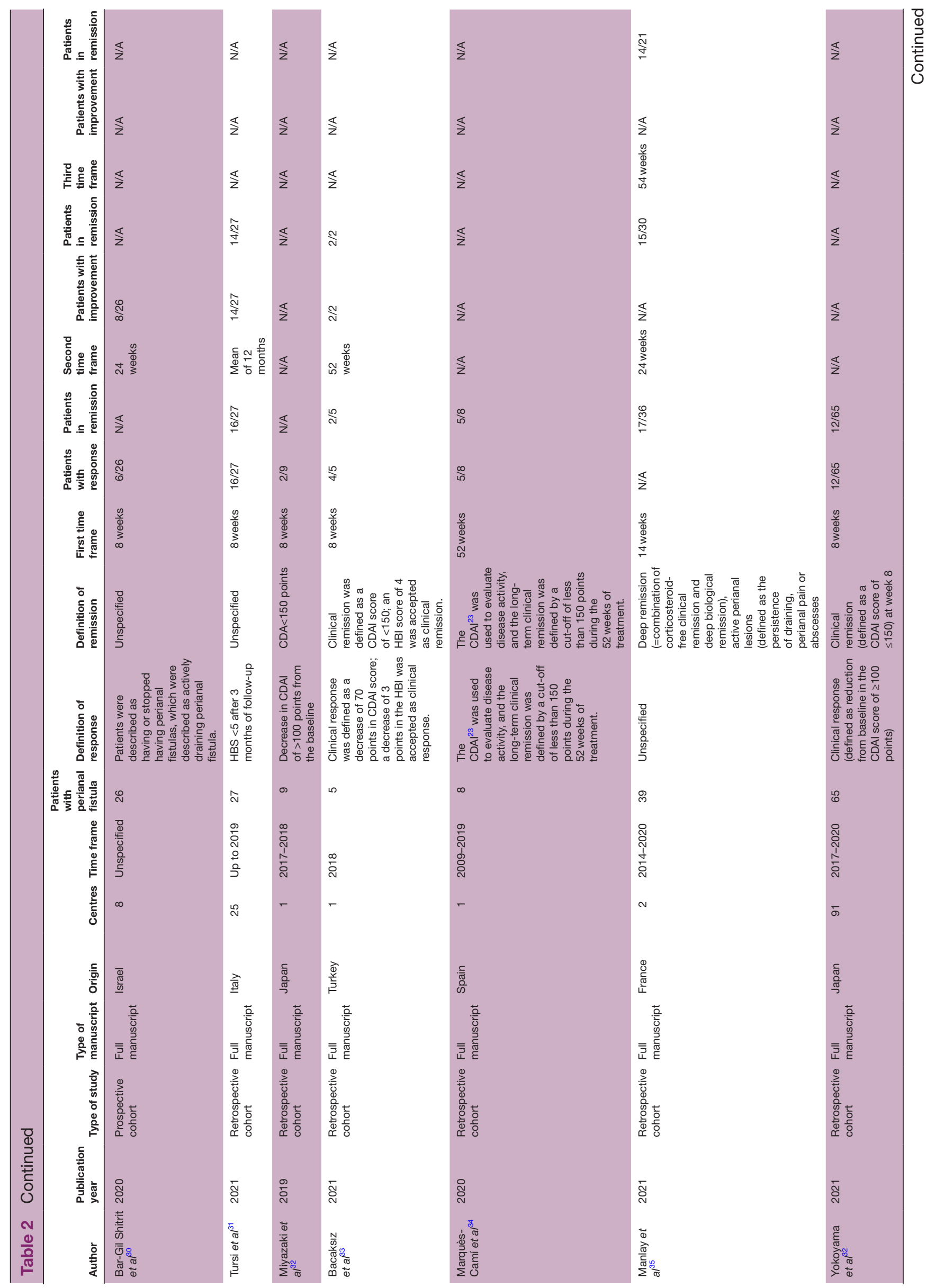




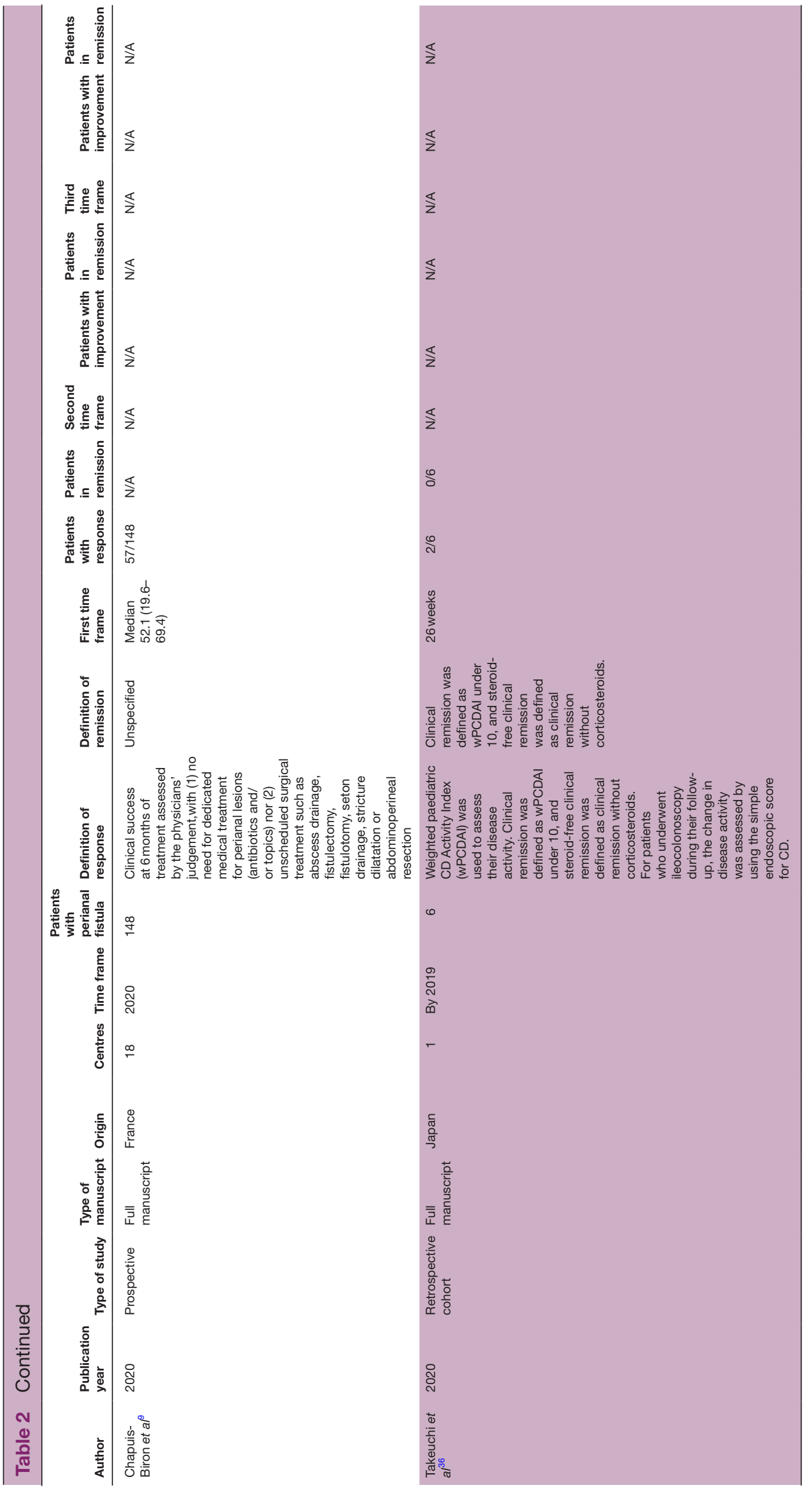




\section{Outcomes}

From the 25 studies included and the patients from our centre, a total of 774 patients with active perianal disease received ustekinumab induction and 71 received placebo. The outcomes were divided in groups of patients based on follow-up time from ustekinumab induction: 8-12 weeks, 5.5-6 months, and 12 months. Of the 348 patients who had data available 8-12 weeks after induction, $110(31.6 \%)$ presented with perianal improvement. Of 279 patients that had information regarding remission, $69(24.7 \%)$ had fistula remission. From the 209 patients who had 6-month follow-up after induction, $92(44 \%)$ experienced perianal fistula response and out of the 53 patients that had data on remission, 18 $(33.9 \%)$ achieved remission. At 12 months, 152 patients had a follow-up, out of which 85 (53.9\%) achieved response, and out of 105 patients that had information regarding remission, $44(41.9 \%)$ achieved it. The definitions of response and remission varied among studies and are described in table 2. Six studies used means and medians to describe time frames, so those patients were not included in the analysis: Chapuis-Biron et al included 148 patients, and after a median follow-up of 52.1 (19.669.4) weeks, $57(38.5 \%)$ patients presented with fistula response defined as clinical recovery per clinician appreciation. ${ }^{9}$ A study by Bishop et al included two paediatric patients, and after a mean follow-up of $11 \pm 4.9$ months, one $(50 \%)$ patient achieved fistula response. ${ }^{10}$ Harris et al included eightpatients with a median follow-up of 14.7 weeks (IQR 8.03), and three $(37.5 \%)$ patients had fistula response but none achieved remission. ${ }^{11}$ The study by Khorrami et al included 18 patients with a median follow-up period of 10 months (IQR 5-21) and reported $11(61.1 \%)$ patients experienced fistula response based on physician assessment, remission was not reported. ${ }^{12}$ Satyam et al included 21 patients, and after a mean of 382 days (IQR 64-1271), 7 (33.3\%) presented with fistula response and $2(9.5 \%)$ patients had fistula remission. ${ }^{13}$ Wils et al included 12 patients and after a median follow-up of $39.2 \pm 32.8$ weeks, 8 patients $(66.7 \%)$ presented with fistula response; remission was not reported. ${ }^{14}$

In the post hoc pooled analysis from CERTIFI, UNITI-1 and UNITI-2, 150 patients out of 161 had follow-up data. Thirty-nine $(26 \%)$ of 150 patients treated with ustekinumab had fistula improvement, defined as $>50 \%$ reduction in draining fistulas, at 8 weeks compared with $12 / 71$ $(16.9 \%)$ patients treated with placebo. A total of $37 / 150$ $(24.7 \%)$ showed complete fistula resolution defined as $100 \%$ reduction in draining fistulas compared with $10 / 71$ $(14.1 \%)$ in the placebo group. At 22 weeks, 9/19 (47\%) had fistula improvement with ustekinumab compared with $6 / 20(30 \%)$ on placebo, and at 44 weeks, $80 \%$ $(12 / 15)$ of patients treated with ustekinumab achieved fistula improvement compared with $45.5 \%(5 / 11)$ in the placebo group. ${ }^{15}$

\section{DISCUSSION}

Perianal fistulae are a complicated manifestation of CD. The data for efficacy of therapies in pCD remain limited. Our study evaluated the rates of response and remission of pCD to ustekinumab through a single-centre cohort study combined with a systematic review and metaanalysis. Overall, our data show a modest response rate and low complete remission rate of perianal disease with ustekinumab therapy.

The retrospective cohort portion of our study found that at 6 months, $48.1 \%$ of patients had perianal fistula response based on provider exam, and $59.3 \%$ of patients reported symptomatic improvement in fistula drainage and discomfort, with $3.7 \%$ of patients reporting complete symptomatic remission marked by complete resolution of fistula drainage and pain. In patients who did not have an initial adequate response, dose escalation was a beneficial strategy, with a $50 \%$ clinical improvement in patients whose doses were escalated to every 4 or 6 weeks. A sustained perianal fistula response based on provider exam was observed in $55.6 \%$ of patients who had 12-month follow-up without new abscesses, fistula formation or antibiotic requirements. All patients (9/9) with 12-month follow-up had symptomatic response with $22.2 \%$ achieving symptomatic remission. There was an excellent safety profile with minimal adverse events.

For the second portion of this study, we performed a systematic review with meta-analysis to have a comprehensive overview of ustekinumab's effectiveness in perianal fistula healing. A total of 25 independent studies including ours were included in the analysis. We found that out of 209 patients with active perianal fistulas that had a 6-month follow-up, there was a $44 \%$ clinical response rate, and of 152 patients with 12-month follow-up, $53.9 \%$ achieved clinical response.

The only randomised controlled data in the systematic review are a post hoc pooled analysis of the data from CERTIFI and UNITI trials ${ }^{15}$ consisting of 150 patients treated with ustekinumab and 71 patients treated with placebo. At 8-week follow-up, fistula response was achieved in $26.0 \%$ of patients treated with ustekinumab compared with $16.9 \%$ fistula response in placebo patients $(\mathrm{p}=0.14)$. The rate of complete fistula resolution at 8 weeks was $24.7 \%$ in ustekinumab-treated patients compared with $14.1 \%$ in placebo patients $(\mathrm{p}=0.073)$. Week 22 results from the CERTIFI maintenance trial, which rerandomised intravenous responders and nonresponders to subcutaneous ustekinumab or placebo, found $9 / 19(47 \%)$ and $6 / 20(30 \%)$ responses, respectively. IM-UNITI contained week 44 maintenance data in a small subset of patients that showed fistula response in $12 / 15(80 \%)$ of ustekinumab-treated patients compared with $5 / 11(45.5 \%)$ placebo-treated patients $(\mathrm{p}=0.64)$. Although there was a trend towards efficacy in fistula healing with ustekinumab, it did not meet clinical significance. ${ }^{16}$ The recently published 5-year extension data from the IM-UNITI trial demonstrated that at week 252, 24 of $31(77.4 \%)$ patients with perianal fistulas had fistula 
response $(\geq 50 \%$ reduction in the number of draining fistulas). ${ }^{17}$

These results are encouraging and suggest ustekinumab may be an additional option to anti-TNFs for perianal fistulising disease, but remission rates remain low. Ustekinumab dose escalation for the treatment of perianal fistulas has recently been studied with promising results, such as Glass et al, who demonstrated $50 \%$ $(12 / 24)$ of patients with active perianal disease showed evidence of improvement after dose escalation. ${ }^{18}$

The results from our cohort study and systematic review and meta-analysis are in concordance with those found by Attauabi et al in their systematic review and meta-analysis evaluating the efficacy of ustekinumab for active perianal fistulising CD. ${ }^{19}$ Our meta-analysis builds on theirs by including additional more recently published studies, and furthermore, we individually contacted authors of studies that did not contain full perianal fistula data.

Our cohort study has several strengths, which include the ability to report rates of fistula response based on provider exam as well as patient-reported symptoms at 6 and 12 months following ustekinumab induction due to standardised exams and templates in our IBD centre, and physical examination was performed by the same provider for each patient. Additionally, endoscopic and serological responses were able to be extracted and reported on a number of included patients to correlate with fistula response and remission. The systematic review included a large number of patients with active pCD treated with ustekinumab to better determine the efficacy of ustekinumab for the treatment of perianal fistulae.

There are several limitations to consider in our study. The cohort study was retrospective and lacked a placebo comparison group. Due to the retrospective nature of the study, there are missing data as well as a number of patients lost to follow-up. Our outcomes for response and remission included physician global assessment, which is known to be a subjective measure. Due to this limitation, we also included patient-reported symptom improvement and remission, which is collected standard at each visit. Additionally, the endoscopy data lacked formal objective endoscopy scoring. In an attempt to overcome this, we limited endoscopy findings to the rectum, which is associated with the perianal disease severity, and we reviewed the images and reports for each patient and classified as rectal response, remission or no improvement. As a tertiary referral centre, the patients in the retrospective study were largely refractory patients without any biologically naive patients. This could underestimate the efficacy of ustekinumab in fistula healing if ustekinumab would be used first line. In our systematic review, the majority of included studies were retrospective with variability in the definitions of perianal fistula response and remission as well as different time points used to evaluate the efficacy of ustekinumab. Data regarding prior biologic use, detailed disease phenotype and endoscopic and serological information were not available in the majority of studies.
In conclusion, ustekinumab is a promising medication for the treatment of pCD with an excellent safety profile. Further prospective studies with a larger patient population and long-term follow-up are needed to further establish the efficacy of ustekinumab in the treatment of pCD.

\section{Author affiliations}

${ }^{1}$ Department of Gastroenterology \& Hepatology, Johns Hopkins University, Baltimore, Maryland, USA

${ }^{2}$ Department of Gastroenterology, Oklahoma University Medical Center, Oklahoma City, Oklahoma, USA

${ }^{3}$ Department of Internal Medicine, St Joseph's University Medical Center, Paterson, New Jersey, USA

${ }^{4}$ Department of Gastroenterology, University of California Los Angeles, Los Angeles, California, USA

${ }^{5}$ Department of Internal Medicine, Johns Hopkins Medical Institutions Campus, Baltimore, Maryland, USA

${ }^{6}$ Rawalpindi Medical College, Rawalpindi, Pakistan

Twitter Gala M Godoy Brewer @drgalagb

Contributors GMGB and AP participated in the conception and design of the project; GGB, GS, ZH, MAA, and MT participated in data collection; GMGB, AMP, and GS contributed to the drafting of the article; AMP, GS, FMS, JM, ML and BNL participated in the critical revision of the article for intellectual content; BL participated in the analysis and interpretation of the data; GMGB, GS, MAA, BNL, $\mathrm{ZH}, \mathrm{MT}, \mathrm{JM}, \mathrm{ML}, \mathrm{FMS}$, and AMP contributed in the final approval of the article. AMP is the guarantor of this article.

Funding This work was supported by The Leona M. and Harry B. Helmsley Charitable Trust (grant number G-2019PG-CD025).

Competing interests None declared.

Patient consent for publication Not applicable.

Provenance and peer review Not commissioned; externally peer reviewed.

Data availability statement No data are available. Anonymised patient level data available upon reasonable request.

Supplemental material This content has been supplied by the author(s). It has not been vetted by BMJ Publishing Group Limited (BMJ) and may not have been peer-reviewed. Any opinions or recommendations discussed are solely those of the author(s) and are not endorsed by BMJ. BMJ disclaims all liability and responsibility arising from any reliance placed on the content. Where the content includes any translated material, BMJ does not warrant the accuracy and reliability of the translations (including but not limited to local regulations, clinical guidelines, terminology, drug names and drug dosages), and is not responsible for any error and/or omissions arising from translation and adaptation or otherwise.

Open access This is an open access article distributed in accordance with the Creative Commons Attribution Non Commercial (CC BY-NC 4.0) license, which permits others to distribute, remix, adapt, build upon this work non-commercially, and license their derivative works on different terms, provided the original work is properly cited, appropriate credit is given, any changes made indicated, and the use is non-commercial. See: http://creativecommons.org/licenses/by-nc/4.0/.

ORCID iD

Gala M Godoy Brewer http://orcid.org/0000-0003-4022-8942

\section{REFERENCES}

1 Gajendran M, Loganathan P, Jimenez G, et al. A comprehensive review and update on ulcerative colitis. Dis Mon 2019;65:100851.

2 Panés J, Rimola J. Perianal Fistulizing Crohn's disease: pathogenesis, diagnosis and therapy. Nat Rev Gastroenterol Hepatol 2017;14:652-64.

3 Panes J, Reinisch W, Rupniewska E, et al. Burden and outcomes for complex perianal fistulas in Crohn's disease: systematic review. World J Gastroenterol 2018;24:4821-34.

4 Mak WY, Mak OS, Lee CK, et al. Significant medical and surgical morbidity in perianal Crohn's disease: results from a Territory-Wide study. J Crohns Colitis 2018;12:1392-8. 
5 Feagan BG, Sandborn WJ, Gasink C, et al. Ustekinumab as induction and maintenance therapy for Crohn's disease. $N$ Engl J Med 2016;375:1946-60.

6 Sandborn WJ, Rutgeerts P, Gasink C, et al. Long-Term efficacy and safety of ustekinumab for Crohn's disease through the second year of therapy. Aliment Pharmacol Ther 2018;48:65-77.

7 Steinhart AH, Panaccione R, Targownik L, et al. Clinical practice guideline for the medical management of perianal Fistulizing Crohn's disease: the Toronto consensus. J Can Assoc Gastroenterol 2018;1:141-54.

8 Guyatt GH, Oxman AD, Vist GE, et al. Grade: an emerging consensus on rating quality of evidence and strength of recommendations. BMJ 2008;336:924-6.

9 Chapuis-Biron C, Kirchgesner J, Pariente B, et al. Ustekinumab for perianal Crohn's disease: the BioLAP multicenter study from the GETAID. Am J Gastroenterol 2020;115:1812-20.

10 Bishop C, Simon H, Suskind D, et al. Ustekinumab in pediatric Crohn disease patients. J Pediatr Gastroenterol Nutr 2016;63:348-51.

11 Harris RJ, McDonnell M, Young D, et al. Early real-world effectiveness of ustekinumab for Crohn's disease. Frontline Gastroenterol 2020;11:111-6.

12 Khorrami S, Ginard D, Marín-Jiménez I, et al. Ustekinumab for the treatment of refractory Crohn's disease: the Spanish experience in a large multicentre open-label cohort. Inflamm Bowel Dis 2016;22:1662-9.

13 Satyam VR, Zullow S, Noronha A, et al. Mo1875 - Efficacy of Ustekinumab in Patients with Refractory Perianal Crohn's Disease in a Tertiary Care IBD Center. Gastroenterology 2018;154:S834.

14 Wils P, Bouhnik Y, Michetti P, et al. Long-Term efficacy and safety of ustekinumab in 122 refractory Crohn's disease patients: a multicentre experience. Aliment Pharmacol Ther 2018;47:588-95.

15 Sands BE. Fistula Healing in Pivotal Studies of Ustekinumab in Crohn's Disease. In: Christopher G, ed. American gastroenterological association. Elsevier, 2017: S185.

16 Lee MJ, Parker CE, Taylor SR, et al. Efficacy of medical therapies for fistulizing Crohn's disease: systematic review and meta-analysis. Clin Gastroenterol Hepatol 2018;16:1879-92.

17 Sandborn WJ, Rebuck R, Wang Y. Five-Year Efficacy and Safety of Ustekinumab Treatment in Crohn's Disease: The IM-UNITI Trial. Clinical Gastroenterology and Hepatology 2021;105.

18 Glass J, Alsamman Y, Chittajallu P, et al. 26 Ustekinumab dose escalation effective in real-world use for luminal and perianal crohn's disease. Inflamm Bowel Dis 2020;26:S76.

19 Attauabi M, Burisch J, Seidelin JB. Efficacy of ustekinumab for active perianal Fistulizing Crohn's disease: a systematic review and meta-analysis of the current literature. Scand $J$ Gastroenterol 2021;56:53-8.

20 Weaver KN, Gregory M, Syal G, et al. Ustekinumab is effective for the treatment of Crohn's disease of the pouch in a multicenter cohort. Inflamm Bowel Dis 2019;25:767-74.

21 Chavannes M, Martinez-Vinson C, Hart L, et al. Management of paediatric patients with medically refractory Crohn's disease using ustekinumab: a Multi-Centred cohort study. J Crohns Colitis 2019;13:578-84.
22 Krugliack N. Ustekinumab Provides Steroid-Sparing and Perianal Improvement in IBD Patients: Single Center Experience. In: Inessa N ed. The American Journal of gastroenterology. The American College of Gastroenterology, 2018: S8.

23 Battat R, Bessissow T, Strohl M, et al. Ustekinumab for the Treatment of Perianal Fistulas in Patients with Crohn's Disease. Gastroenterology 2017;152:S407-1.

24 Tsistrakis S, Oikonomou I. Real-Life data on the use of ustekinumab for the treatment of fistulas in patients with Crohn's disease. Am J Gastroenterol 2017;112:S361.

25 Ma C, Fedorak RN, Kaplan GG, et al. Clinical, endoscopic and radiographic outcomes with ustekinumab in medically-refractory Crohn's disease: real world experience from a multicentre cohort. Aliment Pharmacol Ther 2017;45:1232-43.

26 Kopylov U, Afif W, Cohen A, et al. Subcutaneous ustekinumab for the treatment of anti-TNF resistant Crohn's disease--the McGill experience. J Crohns Colitis 2014;8:1516-22.

27 Attauabi M, Burisch J, Seidelin JB. Efficacy of ustekinumab for active perianal Fistulizing Crohn disease: a Double-Center cohort study. Inflamm Bowel Dis 2021;27:e37-8.

28 Straatmijer T, Biemans VBC, Hoentjen F, et al. Ustekinuma B for Crohn's disease: two-year results of the initiative on Crohn and colitis (ICC) registry, a nationwide prospective observational cohort study. J Crohns Colitis 2021;15:1920-30.

29 Plevris N, Fulforth J, Siakavellas S, et al. Real-World effectiveness and safety of ustekinumab for the treatment of Crohn's disease: the Scottish ustekinumab cohort. J Gastroenterol Hepatol 2021;36:2067-75.

30 Bar-Gil Shitrit A, Ben-Ya'acov A, Siterman M, et al. Safety and effectiveness of ustekinumab for induction of remission in patients with Crohn's disease: a multicenter Israeli study. United European Gastroenterol J 2020;8:418-24.

31 Tursi A, Mocci G, Cuomo A, et al. Real-Life efficacy and safety of ustekinumab as second- or third-line therapy in Crohn's disease: results from a large Italian cohort study. Eur Rev Med Pharmacol Sci 2021;25:2099-108

32 Miyazaki T, Watanabe K, Kojima K, et al. Efficacies and related issues of ustekinumab in Japanese patients with Crohn's disease: a preliminary study. Digestion 2020;101:53-9.

33 Bacaksız F, Arı D, Gökbulut V, et al. One-Year real life data of our patients with moderate-severe Crohn's disease who underwent ustekinumab therapy. Scott Med J 2021;66:152-7.

34 Marquès-Camí M, Robles Alonso V, Borruel N, et al. Normalization of long-term quality of life in Crohn's disease patients receiving ustekinumab. Rev Esp Enferm Dig 2021;113:313-7.

35 Manlay L, Boschetti G, Pereira B, et al. Comparison of short- and long-term effectiveness between ustekinumab and vedolizumab in patients with Crohn's disease refractory to anti-tumour necrosis factor therapy. Aliment Pharmacol Ther 2021;53:1289-99.

36 Takeuchi I, Arai K, Kyodo R, et al. Ustekinumab for children and adolescents with inflammatory bowel disease at a tertiary children's hospital in Japan. J Gastroenterol Hepatol 2021;36:125-30. 